\title{
Correction to: Range Queries
}

\section{Correction to: \\ Chapter 9 in: A. Laaksonen, Guide to Competitive Programming, Undergraduate Topics in Computer Science, https://doi.org/10.1007/978-3-030-39357-1}

The original version of the book was inadvertently published with an incomplete code in Chap. 9 and it has been updated.

The chapter has been updated with the change and the correct presentation is given here;

The following function calculates the value of $\operatorname{sum}_{q}(a, b)$ :

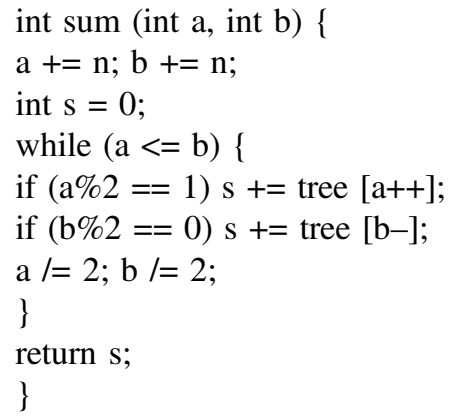

